\title{
Complexity, Methodology and Method: Crafting a Critical Process of Research
}

\author{
MICHEL ALHADEFF-JONES \\ Université de Fribourg (Switzerland) \\ Teachers College, Columbia University (United States) \\ Laboratoire EXPERICE, Université de Paris 8 (France)
}

\begin{abstract}
This paper defines a theoretical framework aiming to support the actions and reflections of researchers looking for a 'method' in order to critically conceive the complexity of a scientific process of research. First, it starts with a brief overview of the core assumptions framing Morin's "paradigm of complexity" and Le Moigne's "general system theory". Distinguishing 'methodology' and 'method', the framework is conceived based on three moments, which represent recurring stages of the spiraling development of research. The first moment focuses on the definition of the research process and its sub-systems (author, system of ideas, object of study and method) understood as a complex form of organization finalized in a specific environment. The second moment introduces a matrix aiming to model the research process and nine core methodological issues, according to a programmatic and critical approach. Using the matrix previously modeled, the third moment suggests conceiving of the research process following a strategic mindset that focuses on contingencies, in order to locate, share and communicate the path followed throughout the inquiry.
\end{abstract}

What teaches us to learn, that is the method. I am not furnishing the method; I am starting out on the search for the method. I am not starting out with a method; I am starting out with the refusal to simplify, taken fully consciously.

- Edgar Morin (1977/1992, p.16)

\section{Introduction}

Thirteen years ago, when I started my doctoral research, I knew what was going to be my topic, but I had no idea how I was going to explore it. My only certainty at that time was that I wanted to explore how the idea of 'sens critique' (critical sense) was conceived in education, and how its development was theorized. With a background in psychology, I also knew that starting with my own experience would be relevant, in 
order to identify tacit assumptions and challenge theories I was tempted to privilege. Neither did I anticipate what kind of journey it was going to be, nor could I have imagined what would emerge from it. If one of the finalities of my research was clear, it took me nevertheless three years to be able to identify what was going to be my 'epistemic position', recognizing in Morin's "paradigm of complexity" the values and assumptions that were the closest to my own. It took approximately another year before I identified Le Moigne's "general system theory" as a key component of my strategy of research, along with Ardoino's "multireferential" interpretation of complexity (Ardoino, 1993). It was only three years after I started that I was able to formulate a first plan scaffolding should I say - for the dissertation. At that time, I was already well involved in the theoretical readings that would constitute one core of my research, exploring with a mix of interest and frustration the 'critical' literature produced in English-speaking educational sciences (Alhadeff-Jones, 2010). At the same time, I was determined to identify sources that would help me figure out how to organize the significant amount of references collected, the heterogeneity of perspectives adopted, my own implication in the process and the epistemological challenges that were raised at each step of the inquiry, when I was driven to challenge the compartmentalization and the reduction that were framing most of my readings (ibid.). The following years brought me to focus more explicitly on the second core of my research: the idea of 'complexity' and how it could inform the notion of 'critique' in education.

Retrospectively, it appears clearly that I would have been unable - when formally required - to submit a plan describing the procedure to be implemented in order to conduct my research. It took me seven years to learn to identify and organize the orders and the disorders constitutive of my topic of research. It is not that I did not try - how many plans did I write! - it is just that there was no ready-made procedure to guide my inquiry. It has taken this whole journey in order to identify the authors, colleagues and friends whom I could trust, and the organizations where I could work and share my thinking. It has taken as much time to learn what my epistemic position was and what is worth 'fighting' for, from an intellectual perspective. I could have easily failed if I did not benefit from the support of my wife and my colleagues, and from a kind of stubbornness. As I traveled with these others (metaphorically, but also literally from Switzerland to the United Stated and then back to France), I eventually produced what I was desperately looking for: a kind of method guiding my choices and informing my decisions.

Today, this initial research grounds most of my academic work. It does not carry any universalist claim. Its value remains limited to a set of finalities and the environment that contextualized it. Nevertheless, multiple learning opportunities emerged from this process; some of them inform my current reflection on 'method' and 'methodology'. Based on this experience, this paper proposes a framework aiming to support the actions and reflections of researchers looking for a method in order to conceive the complexity of a scientific process of research. In order to locate the position adopted, this paper starts with a brief overview of some core assumptions framing the constructivist interpretation characterizing the adoption of Morin's "paradigm of complexity" and Le Moigne's "general system theory". The method proposed in this paper is organized around three 'moments' (Lefebvre, 1961/1991). It represents in fact the fabric of an experience that could hardly be described according to a linear argument. Those three moments require, therefore to be conceived in a circular way as part of the spiraling development of research. 
MICHEL ALHADEFF-JONES

\section{Theoretical background}

\section{Morin's paradigm of complexity}

\section{Epistemological assumptions}

Morin's “paradigm of complexity" (Morin, 1973, 1977/1992, 1977-2004/2008; 1982 / 1990, $1990 / 2008$ ) fundamentally challenges the ways one conceives of knowledge production, from epistemological, psycho-socio-anthropological and ethical points of view. Morin assumes that any knowledge suggests the selection of significant data and the rejection of non-significant data, separating, uniting, organizing into a hierarchy, and centralizing information. By locating his reflection at the paradigmatic level, he denounces the principles that implicitly govern a way of thinking he designates as "paradigm of simplification" (Morin, 1982/1990; 1990; Alhadeff-Jones, 2010). Conceived as both antagonistic and complementary with the principles framing the paradigm of simplification, Morin (ibid.) formulates the hypothesis of a "paradigm of complexity" conceived around the conjunction of the following principles: (1) promoting interpretations starting from the local and the singular; (2) recognizing and integrating the irreversibility of time and the necessity to include history in any description or explanation; (3) recognizing the impossibility of isolating single elementary units and the necessity to link the knowledge of any elements to the knowledge of the wholes they belong to; (4) the principle that organization and self-organization represent problematics that cannot be ignored; (5) the principle of complex causality (including mutual causalities, feedback loops, etc.); (6) interpreting phenomena through the circular logic linking order, disorder, interactions and organization; (7) the principle of distinction, instead of disjunction, between the object, or the subject, and their environment; (8) the principle of relationship between the observer/designer and the object of study; (9) the possibility of a scientific theory of the self and the necessity to recognize physically, biologically, and anthropologically, the categories of being and existence, as well as the notion of autonomy (e.g., through a theory of self-production and self-organization); (10) the recognition of the limits of logical demonstration with formal complex systems (e.g., Gödel, Tarski) and the discursive principle privileging the association of complementary, concurrent and antagonistic notions with each other; and finally (11) thinking dialogically and through macro-concepts, as a strategy of research aiming to establish and question links and relationships between notions and concepts, and by extension between and beyond disciplines.

\section{Morin's Method}

At the beginning the word method signified advancing along a path. Here we must accept to advance without a path, to make the path by advancing. What Machado said: Caminante no hay camino, se hace camino al andor. The method can be formed only during research; it can be disengaged and formulated only afterwards, at the moment when the term once again becomes the point of departure, this time endowed with method ... The return to the beginning is not a vicious circle, if the voyage, as the word trip is used today, signifies experience from which we come back changed. Then, perhaps, we will have been able to learn by learning. (Morin, 1977/1992, p. 17)

Method here is opposed to the conception called "methodological" where method is reduced to technical recipes. Like the Cartesian method, it must be inspired by a fundamental principle or paradigm. But the difference here is precisely one of paradigm. (Morin, 1977/1992, p.18) 
Going beyond reductionist interpretations of complexity (Alhadeff-Jones, 2008), the paradigm proposed by Morin suggests challenges rather than solutions. The critical stake associated with it requires therefore being able to tolerate the continuous negotiation between order and disorder. It also involves rethinking constantly the organization legitimizing one's own statements. Considering the lack of a granted method to cope with the challenges he raises, Morin's position is grounded in a radical uncertainty. It depends on a permanent process of self-reflection bringing researchers to continuously examine their doubts, their ignorance and their confusion (Alhadeff-Jones, 2007, 2012a). Morin's Method does not provide the reader with any methodological recipes. It illustrates eloquently what is at stake in a critical process of research aiming to embrace complexity and conceived as on-going learning experience. Method is fundamentally grounded in the capacity to access, describe, interpret and challenge the assumptions that frame the way scientific knowledge is organized, and the sociocultural conditions from which it emerges. At its core, the experience of the researcheronce it becomes a shared object of reflection - constitutes a crucial element in order to inform one's scientific choices.

\section{Le Moigne's general system theory}

\section{Epistemological assumptions}

For Le Moigne, once acknowledging the limitations of sophisticated formalisms promoted by complexity theorists such as Weaver, Ashby, Shannon, Marcus, or Simon (Le Moigne, 2001; Alhadeff-Jones, 2008), the ongoing work of defining the idea of complexity requires a renewal of the modalities of representation used in order to describe and interpret what it means. Claiming a constructivist position and embracing Morin's "paradigm of complexity", Le Moigne (2001, p. 196) reminds us that: "complexity is in the code and not in the nature of things":

The complexity of a system is not necessary a property of such system (whatever natural or artificial), it is rather a property of the representation currently available of such a system, described according to one or many codes (or languages), our representation of complexity transforms itself and, with it, the modalities of apprehension that we can give to ourselves... (ibid., pp. 197-198)

Looking for a complex way of thinking involves therefore questioning the method used in order to represent and 'design' complexity (Le Moigne, this volume). For Le Moigne, systemic modeling constitutes a privileged approach. Complexity is therefore conceived as the property of a system that can be modeled, considering the modeler's own implication in the process. Le Moigne's "general system theory" is grounded in four principles. First, the principle of relevance, according to which "any object that we consider is defined in regard to the implicit or explicit intentions of the modeler (Le Moigne, 1977/1984, p. 43). Second, the principle of globalism, which requires one (a) to always consider the object of study as a submerged and active part belonging to a larger whole and (b) to perceive it globally, through its functional relationship with its environment, without necessarily trying to establish at first an accurate picture of its internal structure, whose existence and uniqueness cannot be taken for granted. Third, the teleological principle requires one to (a) interpret the object not by itself, but through its behavior; (b) try not to explain it a priori by reference to a law or a possible structure, but rather understand the behavior and the mobilized resources in connection with the finalities that are freely attributed to it by the modeler; (c) consider the identification of such hypothetical finalities as a rational act; and (d) acknowledge the fact that they may rarely be demonstrated. Fourth, the principle of aggregativity (agrégativité) requires one to (a) acknowledge the fact that any representation is deliberately partisan; (b) look for recipes, which may guide the process of selection of the aggregates considered as 
relevant; and (c) exclude the illusory objectivity of an exhaustive inventory of the elements to consider (Le Moigne, 1977/1984, 2001).

For Le Moigne, the two core assumptions (teleology and openness to the environment) that ground those four principles are at the origin of the epistemological shift provoked by the emergence of the systemic paradigm and its rupture with structuralist assumptions. Structuralism had privileged interpretations locating structures (e.g., psychological, social, linguistic, etc.) at the core of the explanation of a phenomenon and considering its environment as bounded by stable limits. The systemic paradigm suggests rather interpreting an object's behavior (including its function and evolution) through - at least - one finality that can be attributed to it, and through a surrounding environment considered not only as global, but also as open. Structures cannot therefore be taken for granted; they appear as more or less relevant in regard of the projects and environment considered in order to define the object modeled.

Key aspects of the general system theory

At the core of Le Moigne's "general system theory" remains a triangulated definition of the object modeled (and the modeling subject). Any definition relies therefore on a triangulation balancing a functional definition (what the object does when it is interacting with its environment), an ontological definition (what the object is) and a genetic definition (what the object is in its history and therefore in its project). Figure 1 illustrates the space in which the modeler has to position her/himself considering the poles s/he will choose to privilege in the modeling process.

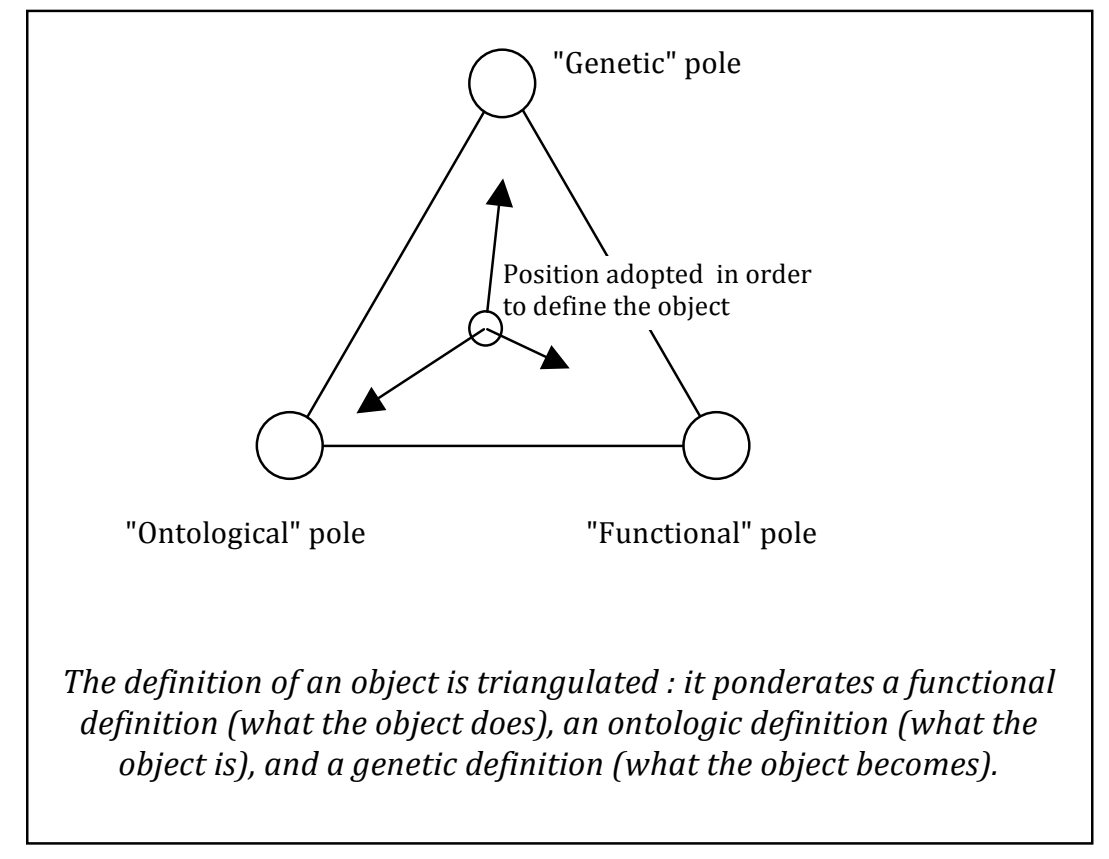

Figure 1: Triangulated definition of an object, based on Le Moigne (1977/1984, p. 64)

On one hand, this conjunction of three definitions - or three modes of modeling characterizes the observer's own position. S/he must be able to communicate it according to intelligible terms (the model); $\mathrm{s} /$ he cannot impose it claiming it is obvious or objective. Any definition not only depends on those three instruments of observation - the three sights (functional, organic, historical) - but also on the relationship 
established between the observer modeling and the object $\mathrm{s} /$ he chooses to study (Le Moigne, 1977/1984, p. 65). On the other hand, any object of study can be considered according to three main aspects that characterize a "general system": active, stable and evolving - in its environment, in regards to its finalities. It is therefore possible to elaborate the 'fabric' of a phenomenon based on the matrix crossing the three ways one can conceive the activity of modeling (functional, organic, historical) with the three aspects which characterize any phenomenon (active, stable, evolving).

\section{Towards a constructivist and complex interpretation of the research process}

Following Morin's considerations, dealing with complexity requires one to negotiate the dialogical relationship between the orders and the disorders constitutive of the research process. Beyond the specific concepts that feed his contribution, Morin's method is grounded in the capacity to tolerate and elaborate the uncertainty emerging once one refuses to simplify the understanding of a phenomenon. Method is a matter of critical self-reflection aiming to constantly challenge the assumptions that frame the progression - and the regression - of the inquiry, considering both the researcher's experience and the conditions framing knowledge production. Method therefore is an emergence produced by the singularity of a research process - an emergence that can be conceived as experiential learning. Following Le Moigne's contribution, it is legitimate to consider that research per se is not complex, but it can be conceived as such by the researcher. Envisioning the complexity of the research process requires therefore elaborating a system of representations - a model - that depicts its complexity, according to a set of principles that define the activity of modeling.

The position adopted in this paper suggests that method and methodology are intertwined aspects constitutive of the fabric of the research process. The framework defined in the following sections is inspired by the method I elaborated throughout my own inquiry (Alhadeff-Jones, 2007). It has been reformulated in order to include notions and concepts that illustrate Morin's "paradigm of complexity", Le Moigne's "general system theory", and results from my own research around the notion of 'critique' in educational research. This framework does not claim to be exhaustive or universal. It is a modest attempt to reflect on the ingredients and the dynamics that may be constitutive of a critical process of research. It suggests adopting an approach organized around three moments: (1) conceiving the research process as a system made of sub-systems (author, system of ideas, object of study and method) characterized by their finalities and their environments; (2) conceiving the research process through a model framing its core methodological issues; (3) developing the research process according to a strategic mindset.

\section{Moment \#1: Conceiving the research process as a system finalized in an environment}

The first moment encourages one to consider the research process, from a systemic point of view, as finalized in an environment. From this perspective, the method implemented is part of a network of elements (I will call them "sub-systems"), which are constitutive of the research project, and that can be defined through their own respective finalities and environments. At least four sub-systems need to be identified in order to conceive what is at stake in the research process. 


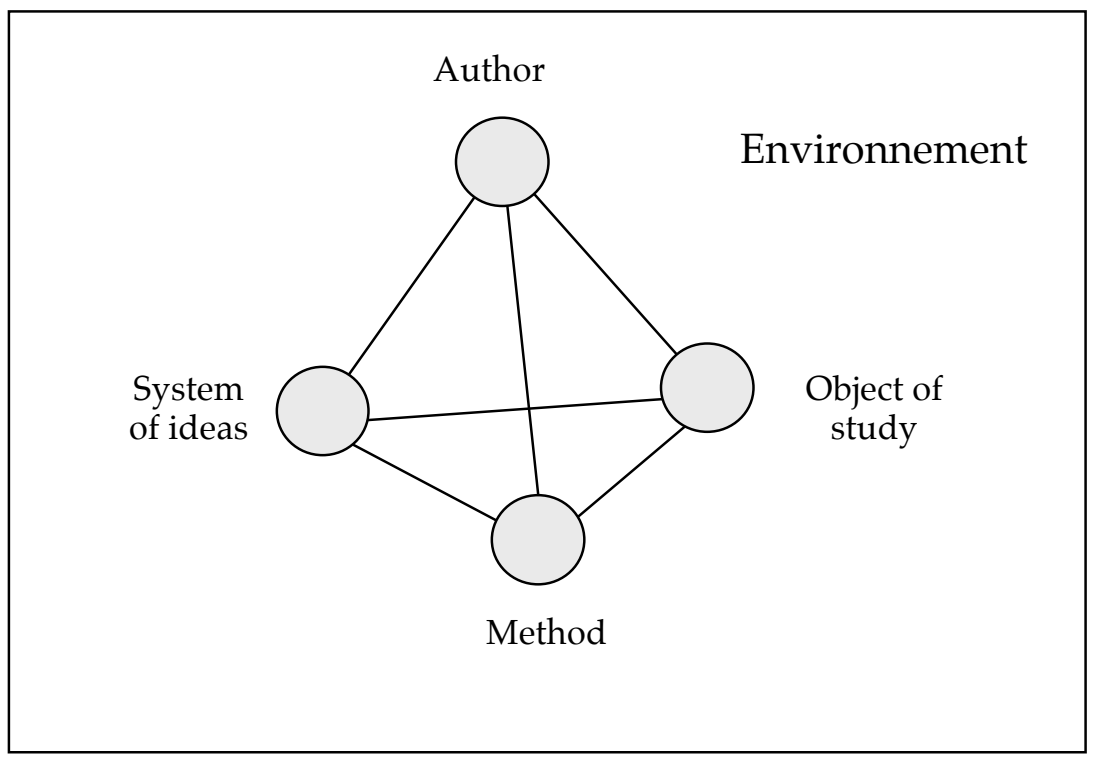

Figure 2: The research process as a system finalized in an environment (inspired by Alhadeff-Jones, 2007, p. 551)

\section{The sub-system "author"}

The sub-system "author" is constituted by the entity(ies) whose finality is to produce (e.g., create, invent, discover, uncover, formulate, etc.) specific knowledge through a research process. Such a process of production includes for instance conceiving the research design, collecting data, conducting interviews, writing, as well as providing resources (material and intellectual) in order to sustain the research process. Common sense usually reduces the definition of the author to a single person (e.g., doctoral student, scholar, etc.) but in fact it always involves more than one entity (including the team of research, the participants involved, the institutions that produce it, etc.) who may or may not be acknowledged depending on the authors' own epistemology. Therefore the notion of "author" should not be taken for granted and reduced to the person who is "writing" the research. To some extent, the authorship of a research involves the community of researchers referenced (or not!), the colleagues and members of the institution(s) in which the research is produced, the participants of the study, etc. According to sociomaterial approaches, it may also be critical to consider the "author" not necessary as a "living person", but eventually as part of a system of relationships including non-human beings (Fenwick \& Richard, 2011). In this text, I will refer to the sub-system "author" as "the author" in order to make the readability easier.

\section{The sub-system "system of ideas"}

For Morin (1991, p. 129) a "system of ideas" is constituted by the "constellation of concepts associated and closely interlinked, whose combination is established following logical links (or apparently logical), according to axioms, assumptions and underlying principles of organization..." A system of ideas includes a core (axioms which legitimate the system, fundamental rules of organization, main ideas), dependant and interdependent sub-systems (e.g., notions, concepts, facts, data, etc.) and defense mechanisms (e.g., in charge of maintaining the integrity and the coherence of the system). The finality of systems of ideas (e.g., scientific theories, religions, mythologies, etc.) is to express statements whose value is considered as true and eventually predicts 
facts and events susceptible to happen. Any system of ideas is at the same time open (it is fed by confirmations and verifications coming from the outside world) and closed (it has to protect itself against degradations and aggressions from outside, threatening its internal order). The level of closure of a system of ideas brings Morin (1991) to distinguish between "theories" and "doctrines", in spite of the fact that even open theories (e.g., scientific ones) have a level of closure, opacity and blindness. This subsystem contains therefore the core assumptions and the principles that define the legitimacy and the logics of the framework adopted by the author in order to apprehend the research process. It usually refers to systems of ideas - such as behaviorism, cognitivism, constructivism, feminism, Marxism, positivism, post-structuralism, psychoanalysis, structuralism, systems theories, etc. - characterized by 'deeply held' epistemic assumptions. Each of these paradigms - and the theories and concepts they privilege - defines and legitimates how knowledge should be produced in order to establish some kind of 'truth' about a phenomenon. Each of them also defines what kind of 'error' should be avoided in the scientific process (ibid.)

\section{The sub-system "object of study"}

The sub-system "object of study" refers at least to two aspects of the research process. On one hand, it is constituted by the practical questions and problems that require finding specific solutions or developing new knowledge. On the other hand, it includes the research problems and questions that offer a ground for the scientific inquiry based on the reformulation of the practical issues taken into account (Booth, Colomb \& Williams, 2003). Organized around practical questions and research problems, the object of study is finalized by the "interest" (Habermas, 1971) that motivates the formulation of explanations and interpretations aiming to address such questions and problems. The formulation of this interest depends as much on the practical issues considered, as it is determined by the author's privileged epistemology (system of ideas). For the sake of clarity, the "object of study" is considered as a distinct entity in this paper, however it is crucial to stress the fact that - as it is the case for the sub-systems "author", "system of ideas", "method" - it never exists as an entity separated from the other elements constitutive of the research process; it should therefore not be reified.

\section{The sub-system "method"}

The finality of the sub-system "method" is to guide the actions constitutive of the research process. It is constituted by the programs and strategies implemented by the author in order to apprehend the specificity of an object of study, according to the principles defined by the system of ideas that $\mathrm{s} /$ he privileges. Literally, a program refers to a set of instructions written in advance. It designates "... a set of codified instructions which, when the specific conditions of their execution appear, allow an apparatus [appareil] to trigger and control defined and coordinated sequences of operations to get to a specific result" (Morin, 1980, pp. 224-225, my translation). The notion of program refers therefore to a predetermined organization of action. Because it only reproduces predefined codes (e.g., embedded physically, biologically or culturally, and expressed through artificial or natural languages), a program requires a steady environment to be executed. It can only manage superficial unknown factors or resistances and it has a low tolerance for errors (ibid.) As it is the case for a program, a strategy involves coordinated sequences of operations. What makes it be distinct is the fact that a strategy is grounded in: "... not only initial decisions triggering [actions], but also [in] successive decisions, taken based on the revolution of the situation; what can bring modifications in the succession or even in the nature of the planned operations ... the strategy constructs, deconstructs, reconstructs itself, based on events, unknown factors [aléas], countereffects, reactions perturbing the ongoing action. [It] requires the aptitude to engage an 
action in uncertainty and to integrate uncertainty in the management of action. Strategy requires skills and initiative." (ibid.) As exemplified by Morin's "Method" (19772004/2008), dealing with complexity suggests that one adopts a mixed approach made of programmatic and strategic operations. In this paper, the sub-system "method" will designate both, methodologies - understood mainly as programmatic approaches - and methods - considered as strategic ones.

\section{The finalities of research}

The way these four sub-systems are organized depends on the research's finalities (e.g., producing knowledge, expressing statements and predicting facts and events, addressing questions and problems, guiding actions, etc.). The research's finalities are not totally predetermined, even if they are usually defined early in the process. The research's finalities emerge from the interrelations between the author, the system of ideas mobilized, the object of study privileged and the method adopted. Between their initial and their final formulations, they evolve. The research finalities appear as the result of a negotiation between the author and the multiple elements evolving in the research's environments. From a modeling perspective, in order to conceive each subsystem of the research process, it is crucial to envision and question their respective finalities.

\section{The environments of research}

Defining the environment of research according to the "paradigm of complexity" suggests that one considers heterogeneous forms of interpretation. The way they are distinguished from each other raises multiple questions and should not be taken for granted. Considering the aim of this paper, I privilege the distinction between physical, living, human and noological spheres, suggested by Morin (1977-2004/2008), assuming that this distinction represents a relevant heuristic approach.

Physical world

Considering the physical world suggests that one defines the research environment based on the natural or artificial objects and phenomena that influence or are influenced by it. Each sub-system of the research process exists to some extent in the physical world and is therefore determined by its evolution. As noted by Fenwick and Richard (2011) there is a long-established tradition of researching the material aspects of education, and recent trends (e.g., sociomaterial approaches) have stressed the importance of reclaiming and rethinking the material practices of education in new ways. Indeed, the built environment (e.g., buildings, classrooms, etc.), the objects that populate it (e.g., tables, desks, boards, lights, etc.) - through their specific configurations - influence the evolution of learning (Fenwick \& Edwards, 2010), as much as the research process is determined by its material ground (e.g., computer, notebooks, books, voice/videorecorder, office, etc.). In addition, it may be critical for researchers to consider the materiality that grounds the systems of ideas unfolding through the research process. Indeed, the materiality, the availability and the configuration (e.g., in libraries, bookstores, or on the internet) of the books, articles and other references accessible - or not - to the researcher play a role in the way choices are made and specific ideas get or do not get privileged. In the same way, the (non) availability of 'virtual' resources (which ultimately remain physical ones) also represent a determining factor influencing the research process. 
Biosphere

Considering the research environment from the angle of the living organisms (e.g., plants and animals) that populate the biosphere may also play a significant role in the way the research process is envisioned and experienced. This is obvious when the research topic refers explicitly to 'ecological' concerns (e.g., environmental education), but it is also be relevant when considering other fields of practice. The example of "ecoformation" envisionned by Pineau (1992; Barbier \& Pineau, 2001) illustrates for instance the role played by the natural environment and its elements (e.g., air, water, earth) in the way one develops specific skills and knowledge.

\section{Anthroposphere}

Considering the anthroposphere suggests one to take into consideration the world of experiences mobilized, lived or developed, paying attention to their heterogeneity (including the marginal, the liminal, the unconscious, the embodied, the affective, stressing the interconnectedness between individuals and their social and cultural environment, etc.). Embracing a holistic perspective and the complexity of the relationships between individual and collective transformations requires one to establish strong connections between psychological, social, anthropological, economical and political dimensions. It also requires one to systematically bind knowledge of parts to knowledge of the whole(s) (Alhadeff-Jones, 2012a). Adopting a systemic and organizational perspective encourages one to conceive learning, education and research through the new properties, which emerge from a whole (individual, organization, institution, society, etc.), influencing its environment and recursively determining its own components (Morin, 1977- 2004/2008). It privileges research design that articulates multiple levels of analysis in order to question what characterizes the relationships among components and how they are intertwined with each other. Adopting a systemic and organizational perspective also invites one to consider the different temporalities (e.g., biological age, generational belonging, local and national history, etc.) shaping learning and how they are intertwined with each other (Alhadeff-Jones, 2013; AlhadeffJones, Lesourd, Roquet \& Le Grand, 2011).

\section{Noosphere}

Finally, it is worth questioning how does one define and apprehend the noosphere - the sphere of ideas and knowledge - that grounds the research process. Here again, it may be relevant - among other conceptions - to follow Morin's distinction between "symbolic-mythical-magical thought" (i.e., symbols, figures, narratives, imagination, models, auras, desires, fears, chance, risks, rituals, irrational, (neo-)myths - which includes the mythology surrounding sciences, etc.), "empirico-rational systems of ideas" (i.e., concepts, logics, axioms, assumptions, principles of organization, theories, doctrines, etc.) and "esthetic-artistic representations" (e.g., art pieces, artistic expressions, etc.) Paying attention to the noological environment of research suggests a consideration not only the rational ideas that populate someone's theoretical world, but also the social and cultural rules and logics that determine the ways they live and evolve (Morin, 1991). At the same time, it also suggests an acknowledgement of the influence of the irrational and symbolic components that determine the way research is conducted, including for instance the researcher's own fears (Devereux, 1967) and themata (Holton, 1978), non-rational beliefs systems, and the symbolic value carried by the study conducted. It finally suggests an apprehension of the research process from an esthetic perspective, paying attention to modes of expressions that include and go beyond language and rationality. 


\section{The organization of research: between orders and disorders}

The considerations developed so far suggest that one apprehend a process of research taking into account the interactions among the author, the system of ideas, the object of study, the method and the way they are organized considering their respective finalities and the environments in which they are evolving. The complexity of this process comes partly from the fact that the elements constitutive of the research sub-systems are both ordered and disordered. They are ordered because they are organized and linked to each other according to some forms of invariance, established relationships, regularity, logic, balance and continuity. At the same time, they are also disordered, because they evolve and vary according to some forms of inequality, agitation, turbulence, chance encounter, rupture, catastrophe, fluctuation, instability, disequilibrium, diffusion, dispersion, etc. (Alhadeff-Jones, 2012b). Therefore considering the research process as a complex phenomenon requires one to be able to organize what is constitutive of its order and disorder. Such a capacity of organization involves the ability to identify not only how the sub-systems are connected and intertwined with each other, but also how each one evolves and how they influence each other following complex forms of causality (retroactive, recursive and dialogic). The position argued in this article is that such a capacity is at the core of a complex method of inquiry.

\section{Moment \#2: Modeling the research process and its method}

Now that some of the core elements constitutive of the research process and the way they are interrelated have been identified, we can start envisioning the second moment of this approach: conceiving them through a system of representations, in other words modeling the way they may interact with each other.

\section{Four assumptions framing the process of modeling the research's method}

At this stage, four main assumptions are framing the way method is conceived. First, it is assumed that it is not only beneficial for the researcher, and the community $\mathrm{s} / \mathrm{he}$ belongs to, but it is also a matter of scientific rigor, to be able to describe systematically the interactions (disordered) and the interrelationships (ordered) between the various elements constitutive of the research process. The possibility to describe and reflect systematically on the research process appears indeed at the core of the method's scientific value. Second, such a systematic description can be conceived - at first according to a programmatic approach (from that angle, the process of modeling can be considered as a 'methodology'). Third, the research process can be modeled from different perspectives, depending on the finalities that are privileged. One can choose to apprehend the research process stressing the intents of the author, the claims associated with the system of ideas mobilized, the interests associated with the object of study or the guidelines privileged by a methodology. Considering both this last hypothesis and the aim of this paper, a fourth assumption is that it is relevant to model the research process highlighting its methodological dimension. From this perspective, the research process can be conceived through the questions raised and the responses given to a set of methodological issues whose organization can be - to some extent - codified, ordered and coordinated by the author, according to principles suggested by a privileged system of ideas (e.g., a scientific paradigm, theories, etc.) in regards to a specific object of study. Based on these four assumptions, the aim of this second moment is to conceive the research process through the formulation of a model organized around a set of methodological issues. As previously discussed, any phenomenon can be considered as stable, active, and evolving 
and can be described through the triangulation of three points of view (functional, organic, and historical). The matrix constituted by the crossing of these two series of three dimensions is at the core of the model used in order to apprehend the research process and its method.

\section{The research process as stable, active and evolving}

Stability, activity and evolution are three states through which the research process and its method can be apprehended. First, considering the research process as stable means that one acknowledges the fact that its sub-systems demonstrate some form of permanence that can be established. From this perspective, the research method is structured by the relative stability of the relationships between the author, the system of ideas and the object of study. Second, considering the research as active suggests one to pay attention to the process of research itself. From this perspective, the research method can be grasped through the co-activity produced by the interactions / interrelations between the author, the system of ideas and the object of study. Third, considering the research process as evolving suggests one to pay attention to the transformations that affects the author, the system of ideas, the object of study and their relationships over time. From this perspective, the research method can be conceived through the specificity of the ways it unfolds and how it affects the evolution of the author, the system of ideas and the object of study.

\section{The triangulation of points of view}

As discussed previously, at least three points of view can be adopted in order to describe the research process and its method. First, a historical perspective suggests one to define the research process considering the genesis and the evolution of the elements that constitute it, as well as their mutual relationships, i.e. what characterizes them from a diachronic perspective. Second, an ontological or organic perspective suggests one to define the research process considering the nature of the elements that constitute it and the nature of their relationships, i.e. what characterizes the way they are organized. Third, a functional point of view suggests one to define the research process considering what is produced by its sub-systems and their mutual relationships, i.e. what characterizes their effects and functions, considering them internally (based on the interrelationships between the authors, the system of idea and the object of study) and externally (considering the surrounding environment).

\section{Modeling the research process and its method}

The matrix constituted by the crossing of these two series of three dimensions [(stability, activity, evolution of the "research process") x (genetic, ontological, functional perspectives adopted in order to describe it)] is at the core of the modeling and can be used to apprehend the research process and its method through nine entries. 


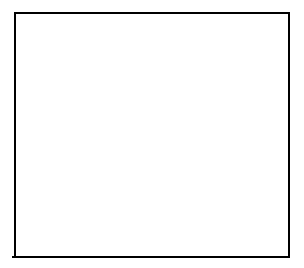

\begin{tabular}{|l|}
\hline $\begin{array}{l}\text { A. Genetic } \\
\text { definition }\end{array}$ \\
\hline $\begin{array}{l}\text { B. Ontological } \\
\text { definition }\end{array}$ \\
\hline $\begin{array}{l}\text { C. Functional } \\
\text { definition }\end{array}$ \\
\hline
\end{tabular}

The research method, whose finality is to guide research actions in an environment (the research process) constituted by the system

"author - system of ideas - object of study" considered as :

1. Structured

A1. Genetic definition
of the research process
considering the co-
structuration of its
sub-systems

-systems

B1. Ontological definition of the

research process considering the costructuration of its sub-systems

C1. Functional definition of the research process considering the costructuration of its sub-systems
A2. Genetic definition of the research process considering the coactivity of its subsystems

B2. Ontological definition of the research process considering the coactivity of its subsystems

C2. Functional definition of the research process considering the coactivity of its subsystems
3. Evolving

A3. Genetic definition of the research process considering the coevolution of its subsystems

B3. Ontological definition of the research process considering the coevolution of its subsystems

C3. Functional definition of the research process considering the coevolution of its subsystems

Figure 3: The matrix used in order to model the research process conceived through its method

A programmatic approach aiming to model the methodological dimensions of a research process requires one to consider systematically the nine entries constitutive of this matrix and the logics that order the procedures they suggest. The following sections formulate examples of questions and guidelines in order to consider each of those nine entries.

A1. How to access, describe and interpret the history of the relationships between the author, its object of study and the system of ideas involved in the research?

This first methodological entry questions the way one conceives from a diachronic perspective what constitutes the consistency and the stability of the relationships between the author, the system of ideas and the object of study.

A first path is to consider the biographical background that informs one's understanding of and interest in a topic of research. In this perspective, Maxwell (2005, p. 27) suggests for instance to write a "Researcher Identity Memo" defining its purpose as following: "... to help you examine your goals, experiences, assumptions, feelings, and values as they relate to your research, and to discover what resources and potential concerns your identity and experience may create. What prior connections (social and intellectual) do you have to the topics, people, or settings? What assumptions are you making, consciously or unconsciously, about these? What do you want to accomplish or learn by doing this study?" Beyond Maxwell's specific recommendations, the task is twofold. 
First, it should bring one to question the origins of the relationship between the author and the object of study: where does the interest manifested toward the object of study come from? How is it rooted in the author's own experience? How does the object of study's own background relate to the research opportunity? Second, it should brings one to describe the history of the relationship between the author and the system of ideas envisioned as relevant in order to apprehend the topic of research: what are the origins of the positive appreciation - or the reluctance - of the author to consider the specific paradigm of research, theory, concepts, representations mobilized by the research process? This first task supposes therefore the adoption of a diachronic sensibility focusing for instance on the history of the author and the people and collectivities involved in the research (Dominicé, 2000).

A second path is also required: being able to identify the history of the relationships between the object of study and the system of ideas mobilized to study it. From a traditional scientific perspective, it suggests one to elaborate a critical literature review (Montuori, this volume; Booth, Colomb \& Williams, 2003; Torraco, 2005), which describes past and current scientific research informing the topic of study. Considering the system of ideas more broadly also suggests one to consider the topic of research at the light of the cultural characteristics that inform the research process: historically, how is the object of study considered and represented (rationally or not) among the researchers, the institutions, and more broadly the community and culture surrounding the author and the participants implicated in the process?

\section{B1. How to access, describe and interpret the actual characteristics, which structure the relationships between the author, its object of study and the system of ideas involved in the research process?}

With this second entry, what is at stake is to define the characteristics that inform and describe the position of the author, the context of the object of study, the system of ideas mobilized, as well as their mutual relationships, considering them again as relatively stable.

Describing what characterizes the systems of ideas that inform the research process (paradigm, core assumptions and hypothesis, theories, concepts, notions, etc.) and the characteristics, which define and contextualize the object of research, both constitute standard research procedures (Denzin \& Lincoln, 2000).

Taking into consideration the author's implications cannot however be taken for granted. Considering the position of the author suggests one to consider her/his implications, i.e. the epistemological, ethical and existential issues that determine one's approach, as they appear influenced by unconscious, emotional, cognitive, social, historical or political determinants. In France, Lourau (1997) defined as "implication" every aspect that intellectuals refuse, consciously or not, to analyze in their practice. Ardoino (1993) establishes a distinction between "libidinal implications" (inherent to unconscious psychic life) and "institutional implications" (inherent to the social, economical, and political status, ideology, etc.). In North-America, close to the concept of "institutional implications", the notion of "positionality" describes how the researcher/practitioner's own class, ethnicity and gender influence one's own research and educational practice (e.g., Johnson-Bailey, 2004; Taylor, Tisdell \& Hanley, 2000). Systematically taking into consideration practitioners and researchers' implications is difficult, not only because it challenges the assumption of neutrality deeply rooted in positivist epistemology, but also because it requires the development of research and pedagogical methods that valorize the practitioner's self-inquiry and reflexivity (Alhadeff-Jones, 2012a; Denzin \& Lincoln, 2000; Alvesson \& Sköldberg, 2000). 
C1. How to access, describe and interpret a priori the functions of the activity of research and what it is expected to produce

This third entry questions the privileged path to follow in order to establish the expected effects and roles played by the various components constitutive of the research process and their relationships.

Generally speaking, one way to consider the effects of the research process is to question how does it potentially increase the autonomy of the people and ideas it involves, i.e. their capacity to define freely the rules one follows. For instance, considering the author, the research process may contribute to extending one's capacity to interpret a phenomenon, but also the possibility to develop one's own authority as a researcher (e.g., the change of status associated with earning a doctoral degree) or to reinforce one's legitimacy in one's field (e.g., university reputation, etc.) Considering the object of study, increased autonomy may get translated through the capacity to solve a problem or at least to understand better what it involves, which may ultimately participate in people's empowerment. From the perspective of the system of ideas mobilized, increasing autonomy may be expressed through the capacity to challenge existing beliefs, knowledge and representations, in order to make them more inclusive, better organized, and less dependant on ill-defined or unchallenged assumptions; it can be translated through the increased authority of a theory.

The adoption of a critical and complex perspective (Alhadeff-Jones, 2007) suggests that one nuance the empowering effects inherent to the nature of research and to question its potential ambivalence. Morin's (1990/2008) principle of 'autonomydependence' reminds us indeed that what makes a system (e.g., a person, a group, a theory, etc.) self-sufficient and autonomous is also what makes it dependent. This principle encourages one to systematically consider the research's functions as a manifestation of the complex interplay between complementary, contradictory and antagonistic forms of self and mutual control (embedded in individuals, groups, institutions, theories, beliefs, etc.) On one hand, the research process can contribute to develop autonomy. On the other hand, the research process may also contribute to foster dependency (e.g., toward specific individuals, institutions, specific practices, or toward specific theories, systems of interpretation, etc.). The research effects may eventually be experienced as disempowering by the people they involved. Such situation emerges when the study design raises ethical concerns. But it is also present when the process explicitly aims to promote participants' empowerment and fails to provide them with appropriate resources (Alhadeff-Jones, 2007, 2010, 2012; Ellsworth, 1992).

The tension between autonomy and dependence is fundamentally embedded in what structures the functions of the research process. From a methodological perspective, it is therefore critical for the author not only to define the research goals, but also to establish how to systematically question their contribution to both the autonomy and dependence of the sub-systems involved in order to critically assess and negotiate such tensions without reducing them.

\section{A2. How to access, describe and interpret the progression of the research process}

This entry brings one to consider the research activity as it unfolds through time. From a methodological perspective, it questions how one conceives the development of the goals, functions and roles played by the author, as well as her/his relationships with the object of study and the system of ideas mobilized. It also supposes to clarify the evolution of how the study of the topic of research informs the system of ideas mobilized and vice versa. 
In my attempt to conceive a complex model of the idea of critique in education (Alhadeff-Jones, 2007), I have suggested that the genealogy of any forms of critique (and research can be interpreted - to some extent - as a critical project) can be apprehended through at least four interrelated and intertwined processes: (a) (re)prise de forme (reshaping); (b) (re)prise de conscience (re-raising awareness); (c) (re)prise de pouvoir (reempowering); and (d) (re)prise de position (re-positioning); the radical "re-" stressing the fact that each of those four processes should be conceived as recurring, circular and therefore ongoing rhythmic phenomena, as they fluctuate through the repetition of some kinds of experience. From this perspective, the questions to consider become therefore: (a) how does one keep track of the evolution of the multiple forms taken by the process of research (e.g., organizations, appearances, styles, principles, meanings inherent to what defines its structure)? How does one describe the evolution of the research process considering the transformation, production and self-production of the research's subsystems? (b) How does one capture the emergence of the new insights produced by the transformation of the research process over time (e.g., reflective activity, but also moral, ethical, social, political insights, etc.)? (c) How does one unveil the evolution of the alienating and empowering dynamics (e.g., forms of autonomy and constraint) shaping - and shaped by - the emergence of new insights and new forms of awareness? Finally, (d) how does one describe the progression through time of the positions - or the repositioning - emerging from the research process (e.g., the ongoing definition of the limits, places, ranks, roles, states, attitudes characterizing the research's components)?

This entry privileges therefore methods that allow one to keep track of the successive steps and stages of the research development. For instance, it suggests that people involved (e.g. author, participants, etc.) keep a journal, describing the evolution of their interest for the research. It may also bring them to write retrospectively an

account of their development throughout the successive phases of the process, or to respond to dedicated questions aiming to retrospectively interpret their evolution. Considering the system of ideas mobilized, it suggests one to establish how ideas, beliefs, notions, concepts and theories have evolved through the research's span.

\section{B2. How to access, describe and interpret the nature of the activity of research?}

Any research claiming some form of criticality can be conceived through at least six functions (Alhadeff-Jones, 2007) - discriminating, interpreting, examining, arguing, judging, and challenging - that emerge from the research process and require a methodology in order to be defined and/or organized.

\section{Discrimination}

Discrimination refers to the activity of differentiating and distinguishing elements from each other in order to process them according to specific treatments (e.g., establishing similarities and differences, identities and otherness, equalities and inequalities, etc.) This activity is at the core of any scientific inquiry, which discriminates human activity based for instance on the characteristics of the people involved (e.g., gender, age, marital status, language spoken, ethnical background, occupation, etc.) 


\section{Interpretation}

Interpretation refers to at least three operations constitutive of the process of meaning making. The first one is a matter of translation, which implies transforming what is discriminated in order to assimilate it according to a set of invariants (e.g., perceptive, linguistic, conceptual, anthropological, etc.). One can for instance discriminate phenomenal differences between men and women's behaviors, but such differences need to be translated through language in order to be acknowledged and discussed (e.g., choosing to refer to "sex" or "gender"). The second operation is to attribute meaning to what is discriminated-translated, according to a specific language (usually disciplinary and theory-based). For instance, choosing to refer to "sexual" versus "gendered" differences impacts the way meaning is produced (e.g., privileging a biologically versus socially based interpretation in order to explain differences of behavior). The third operation is a matter of interpretation, understood as pronunciation and reproduction according to the personal characteristics of the entity, which performs the process (e.g., the way a theory - as a musical piece - is interpreted depends on the preferences of the author-performer who reproduces and adapts previous formulations). For instance, authors who used feminist theories as a critical framework in education have produced heterogeneous forms of academic discourses challenging or reproducing specific "regimes of truth" (Gore, 1993).

\section{Examination}

Examination supposes the capacity to evaluate a phenomenon in order to better appreciate, know or understand it. Beyond discrimination and interpretation, examination involves the adoption of a system of values, norms and standards in order to compare the object of study with a scale, a referential or a system, and determine its value. For instance, in order to establish the influence of gender differences on a specific matter (e.g., algebra or social skills), educational research refers to tests, assessments, grades, criteria of evaluation and comparison, in order to assess boys and girls behaviors at school. As they focus on specific dimensions, such systems of values, norms and standards are never neutral and their legitimacy requires to be argued in order to legitimate the research's aim.

\section{Argumentation}

Argumentation refers to at least three operations aiming respectively to establish evidences, deliberate and communicate around the legitimacy of the way a phenomenon is interpreted and examined. It is at the core of the scientific process: ethnographic observations, as well as statistical analyses, require the researcher to develop an argument in order to be acknowledged as legitimate. The value of such an argument, the way it is discussed among a community of scholars and the way it is shared (e.g., as a research report, dissertation, article) suggest one to pay attention to the evidences (e.g., observations, recording, transcript, measurement, etc.) that are produced and the logics which frame the discourses through which such evidences are elaborated (e.g., forms of rationality, logics, calculus, rules of argumentation, rhetoric, etc.) Key debates usually occur when the assumptions framing the mode of argumentation are at the core of the dissent. For instance, debates - which occurred mostly in the 1990's in the Unites States between supporters of the 'critical thinking movement' (inspired by informal logic) and those advocating for more radical forms of 'critical pedagogy' (based on political analysis), in spite of their common interest for student's critical capacity, were mainly polarized around the role given to language and formal logic. On one hand, argumentation was considered based on the informal logic of discourses; on the other 
hand, discourses themselves (including logical ones) were considered as shaped by social and political dynamics (Alhadeff-Jones, 2010).

Judgment

Judgment is closely intertwined with the activity of discriminating, interpreting, examining, and arguing. The judgmental dimension of research introduces however another dimension. Through the formulation of an opinion, the judgmental function of research establishes some form of authority, involving the adoption of a set of principles, which define what is right or wrong, fair or unfair, balanced or unbalanced, etc. Beyond the normative dimension of research, establishing a judgment questions the research's underlying principles of justice (Boltanski \& Thévenot, 1991) referring to heterogeneous form of balance and equilibration. Indeed, studying gender inequalities at school makes sense mainly if one acknowledges the principle of social and political equality between men and women. The way one defines the principles of such equality (based on cultural, social, economical principles, etc.) is embedded in a political agenda - shaped by history and culture - that cannot be taken for granted. The judgmental dimension of research requires therefore one to establish and eventually question what shapes and defines the researcher's authority to claim specific principles of justice aiming to (re)balance or (re)equilibrate specific phenomena (e.g., observed gender inequalities).

\section{Challenge}

In spite of the researcher's claim of 'neutrality', the aim of any scientific inquiry is to challenge assumptions or produce changes around issues that are never neutral, either psychologically, socially, culturally, economically and/or politically. Discriminating, interpreting, examining, arguing and judging involve activities that contribute to alter, change, modify, but also challenge and put into question the way the research's subsystems and their relationships are apprehended. They may even contribute to put into crisis the author, the system of ideas, the object of study and/or the research method itself. Considering the nature of such challenges suggests one to establish what kind of tensions - or even rupture - may potentially be raised by the inquiry, and what kind of gradient is used in order to describe such tensions.

From a methodological perspective, the aim of considering research's critical functions is therefore to identify how does one access, describe and define what is discriminated, interpreted, evaluated, argued, judged and challenged through the activity of research.

\section{C2. How to access, describe and interpret what is produced by the research activity?}

The product of a scientific inquiry is traditionally associated with the 'results' section of a research report. From a methodological point of view, the issue is usually reduced to the question: how to expose and synthesize the key outcome of a study? From a complexivist perspective, the product of the research process can be interpreted as everything that emerges from its activity and affects the self- and mutual relationships between the author, the object of study, the system of ideas mobilized, and their respective finalities and environments.

Considering the functions previously defined, one way to consider the research activity is therefore to question what are the effects produced by what the process of inquiry actively discriminates, interprets, evaluates, argues, judges, and challenges.

Figure 3 illustrates some of the micro-emergences associated with each of the six critical functions of the research process and the way they interact with each other. The products of the activity of research can therefore be interpreted as any emergences formed through this system. 
From a methodological perspective, the goal is to define the resources used in order to access, describe and interpret what emerges when one produces discriminations, interpretations, examinations, argumentations, judgments, and some forms of challenges through the activity of research. One way to proceed is to question what is learned (from the point of view of the author, the object of study, the system of ideas) when such functions are implemented. Considering the research activity as a more or less openended learning process, this methodological entry suggests therefore one to consider what is assimilated, unfolded, appropriated, transmitted, facilitated and/or co-constructed considering the research functions.

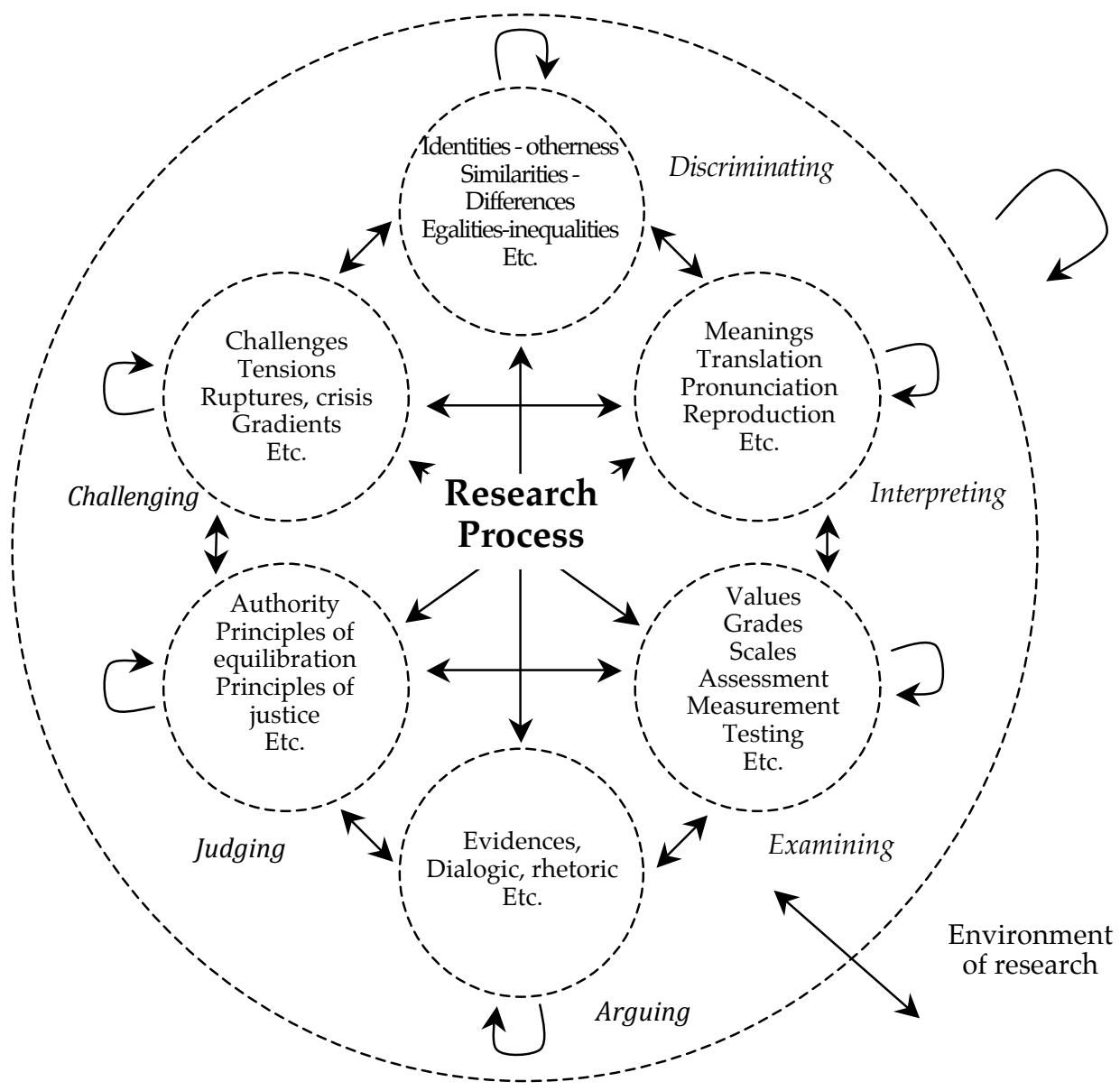

Figure 3 : Six critical functions of the research process, some of their microemergences, and their interrelationships (adapted from Alhadeff-Jones, 2007, p.341)

A3. How to access, describe and interpret the history of how the research process evolves?

As it has already been highlighted in entries A1 and A2, research and its effects unfold through time. If one considers for instance the four processes previously defined in order to interpret the progression of the research process - (re)shaping, (re)raising awareness, (re)empowering and (re)positioning - each of those is characterized by its own temporal dynamics, which depends also on the research's specific functions. For 
instance, educational biography (Dominicé, 2000) - as a specific method of rechercheformation - can be used in order to promote self-reflection, raise (self-) awareness and develop knowledge about lifelong learning dynamics among adult learners. Through autobiographical writing exercises and group discussions, two activities that have their own temporalities, participants can eventually reshape the understanding given to their own life history and inform the researcher's own appreciation of adult learning. Such a process requires both some form of maturity (in order to self-reflect), and the capacity to slow down in order to discriminate, interpret, share, discuss meanings and challenge assumptions emerging from the participants' narratives (activities requiring a specific rhythm, which often conflicts with the fast pace of the everyday life). Such dimensions characterize this method from a temporal perspective (Alhadeff-Jones, 2011, 2013) and make it more or less suitable depending on the learner's characteristics, the environment and the resources available.

More broadly, the evolution of the multiple forms taken by the process of research, the evolution of its capacity to transform, produce and self-produce the organization of the research's sub-systems, the emergence of new insights, the evolution of their alienating and empowering effects, and the progression through time of the positions emerging from the research process, all those dimensions evolve according to specific temporal patterns, which have their own history. Such configurations usually appear through the methods used in order to keep track of the successive steps and stages of the research development (e.g., researcher and/or participant's journal, correspondence, etc.). Because such pattern may raise tensions within the research framework, they cannot be taken for granted. For instance, individual and social expectations shape how much time is allocated to a research project and the way its temporalities are experienced (Ylijoki \& Mäntyla, 2003). From a genealogical perspective, it is therefore important to question how does one apprehend the research process' evolution through time. From a methodological perspective, this entry brings the researcher to question among others - how does one discriminate and interpret the rhythms and the temporalities constitutive of the evolution of the research process (Alhadeff-Jones, 2013)?

\section{B3. How to access, describe and interpret what characterizes the evolution of the relationships between author, object of study and systems of ideas?}

Research methodologies are usually described and represented - mainly for the sake of clarity and communication - according to a linear and ordered progression. However, their implementation rarely follows such a predictable path. This fact encourages one to revisit common assumptions about the type of causality involved in the research process and the way they affect the transformation of the inquiry.

\section{Complex causality}

The principle of 'complex causality' (including mutual causalities, feedback loops, etc.) informs the understanding of self-regulating systems (Morin, 1977-2004/2008). It breaks with the principle of linear causality stressing the fact that cause acts on its effect, as effect acts on its cause through positive and negative feedbacks (exemplified by the thermostat's mechanism of temperature regulation).

Research methodologies are generally described through the linear succession of different phases (identifying a research topic, formulating a research question, preparing a literature review, establishing a plan for collecting data and/or explore theory, collecting data and/or developing theoretical contribution, analyzing and interpreting the data collected, etc.). Each of these phases is organized around multiple choices and activities that affect the author, the system of ideas mobilized, the object of study and their mutual relationships. Each step involves a large variety of outcomes (e.g., discovering new facts or ideas, elaborating interpretations, producing new hypothesis or 
assumptions, improving one's understanding of a situation or a theory, etc.) that impact the other phases of the research process. The principle of complex causality invites one to pay attention to theses mutual relationships, not only through a linear, but also through circular dynamics. It stresses the role of the positive and negative reinforcements (e.g., radicalization and inhibition) that regulate the activity of research, at and between each stage of the process (Alhadeff-Jones, 2012a).

\section{Self-organization and self-production}

Beyond the idea of regulation, complexity theories also introduced the notion of 'recursive loop' in order to understand and describe processes of 'self-organization' and 'self-production' (Morin, 1977/1992). These refer to a generating loop through which products and effects are themselves producers of what produces them. To some extent, research is self-produced because it is created based on the organization of elements (questions, assumptions, representations, theories, facts, interlocutions, etc.) that emerge during the process and reinforce - or eventually inhibit - its own development. Such dynamics is dependant on recursive loops experienced and/or observed by the people involved in the research process. Research emerges therefore from what each stage of its own development produces or mobilizes (e.g., questions, hypothesis, assumptions, theories, facts, observations, interpretations, etc.) Recursive loops stress the relationship between circularity, repetitions and innovation involved in the process of inquiry. Paying attention to these loops provides resources to interpret the generative dynamics associated with scientific inquiry according to linear and non-linear evolutionary perspectives. It is congruent with common experiences establishing the evolving and spiraling nature of research.

Such a perspective is challenging because it claims that single causes and linear paths used to describe the evolution of research are the exception, not the rule. Research is produced and/or inhibited by the multiple changes and effects that are constitutive of the ways the author, the system of ideas and the object of study respectively evolve and mutually interact. According to this assumption, it becomes therefore crucial to establish, from a methodological perspective, how to access, describe and interpret what characterizes the evolution of the relationships between author, object of study and systems of ideas.

\section{Critical masses}

My own research experience (Alhadeff-Jones, 2007) brought me to pay attention to the role played by 'critical masses' produced throughout the research process (e.g., amount of books bought or borrowed, articles collected, people contacted, pages written, etc.). Following the physical analogy, crucial phases of the research process can be interpreted as constitutive of 'chain reactions' contributing - through complex causalities - to the transformation of research (including the author, system of ideas, object of study, etc.). A 'chain reaction' necessitates the presence of a 'critical masse' of elements whose interactions drastically change when their concentration reach a specific threshold considered literally as critical. Such a critical change can contribute to the emergence of a bifurcation in the system's behavior. For instance, the activity of research is produced through processes of accumulation and collection (e.g., books, articles, facts, data, ideas, readings, notes, interpretations, etc.) For each of those processes, the role played by the experience of saturation is crucial; it refers for instance to the point where additional information brings redundancy. Both the experience of redundancy, as well as the subjective experience of reaching critical states (e.g., cognitively, emotionally, intellectually, etc.) represent significant markers of the progression of the inquiry. The amount of time and money spent in specific activities can also be a marker, as much as 
the amounts of people constitutive of the different branches of the research network (e.g., number of subjects, colleagues, readers, etc.). Therefore, from a methodological perspective, accessing, describing and interpreting what characterizes the evolution of research requires - among others - questioning how does one experience and identify thresholds, critical states, bifurcations, saturation or redundancy, emerging - through complex causalities - from the research's masses of information, experiences and people involved.

\section{C3. How to access, describe and interpret what are the effects produced by the research evolution and how to take them into consideration?}

A meaningful research could be defined as a research that facilitates some kind of transition between two states of the research system, characterized by different relationships between the author, the system of ideas, the object of study, in an environment made of both certainties and uncertainties. The transition can contribute to influence, change, or transform systems of ideas mobilized and how they shape the ways one discriminates, interprets, examines, argues, judges and challenges an object of study. The transition can also contribute to affect, change, or transform the identity of the people involved, through the empowerment of the subjects of the study, or through the change of status of the author. Inspired by the notion of "transitional object" (Winnicott, 1971), I have developed (Alhadeff-Jones, 2007) the hypothesis that a scientific inquiry, such as a doctoral research, can represent a "transitional complex", whose critical masses may contribute - beyond the narrow results of the study - to both epistemic and identity transformation.

Some of those changes are predetermined and expected, some are not. According to Morin's principle of "ecology of action" (Morin \& Le Moigne, 1999), once produced, the effects of someone's activity (e.g., the research process) - due to the complex play of interactions involved - rapidly escape from the person's original intent, and have their own life, autonomous of the system from which they emerged. From a complexivist perspective, it is therefore critical to reflect on the spectrum and the loci of effects considered as consequences of the evolution of the research process, not only from an intellectual perspective, but also considering identity, power dynamics, ethical principles, etc.

One way to proceed - among others - is to question the effects produced by the various masses constitutive of the research process (e.g., information, knowledge, physical, financial and social resources, etc.). Considering research as a transitional complex questions more specifically how do its masses contribute - or not - to influence the balance between certainty and uncertainty, predictability and unpredictability, experienced by the people involved in the process. The methodological challenge at this stage is to determine how does one apprehend the evolution of such effects, the nature and the impact they have on the level of certainty and uncertainty experienced about the world, others and oneself.

\section{Moment \#3: Developing a research method}

Moment \#2 suggested apprehending the research process and its method through nine entries in order to describe the structure, the activity and the evolution of the research inquiry. It suggested that one conceive method according to a programmatic view, i.e. a set of instructions aiming to coordinate the operations involved in the research process. In order to be implemented, such a program requires the researcher to conceive how to access, describe and interpret:

- The history of the relationships between the author, its object of study and the system of ideas involved in the research; 
- The actual characteristics, which structure the relationships between the author, its object of study and the system of ideas involved in the research process;

- What are a priori the functions of the activity of research and what it is expected to produce;

- The progression of the research process;

- The nature of the activity of research;

- What is produced by the research activity;

- The history of how the research process evolves;

- What characterizes the evolution of the relationships between author, object of study and systems of ideas;

- What are the effects produced by the research evolution and how to take them into consideration.

Embracing all the possible elements, variables and determinants that have to be taken into consideration in order to address systematically each of those nine methodological dimensions is an impossible task. First, because no research setting enable the full completion of the different layers of exploration suggested previously. Second, because the model envisioned previously has to be considered as an open system; the finalities, the environments, and the relationships between the elements of the model, as well as their evolution through time, are open to the unexpected. According to the principle of aggregativity (Le Moigne, 1977/1984), one has to acknowledge the fact that the modeling of the research method is therefore partisan and requires one to exclude the illusory objectivity of an exhaustive inventory of every single methodological component. Rather than following strictly the methodological program suggested by the matrix, it becomes crucial to adopt a strategic position and decide, based on the contingencies, what are the best ways to navigate through those layers. What is critical, in order to maintain methodological rigor is to be able to identify and locate one's own research trajectory so that it can be understood by others, shared, communicated and to some extent reproduced. This is where the model previously conceived is particularly useful. The third methodological moment suggests one to describe the research process by locating the research's method and methodologies implemented, based on the logics organized by the model, in order to justify and interpret the options chosen or privileged. This is mainly a strategic activity:

Methodologies are guides which a priori program research, but the method that emerge from our line of thought [cheminement] will be a resource for strategy (which will include usefully programmed segments, i.e. "methodological" ones, and necessarily, discovery and innovation)." (Morin, 1986, p. 27, my translation)

How does one learn to develop a strategy of research is mostly a matter of experience; one cannot plan true discovery and innovation. It requires therefore one to be able to tolerate and negotiate uncertainty and unpredictability throughout the research process.

This is why, incapable to assure the exhaustive exploration of the field, aware of the uncertainties and the unknown variables, and fully assuming the bet of a "complex thought", I necessarily used a Blitzkrieg strategy [lightning war]. The cognitive attack aims what was judged as communication center, key problems, crucial knowledge, and it practices "whirling" [tourbillon] as used in soccer game, in order to quickly permutate the plan of attack, in order to look for a breach ... there is a huge risk to misidentify the key problems, the real questions, the good paths of communication, the reliable information. Obviously, I try to protect myself from the risk by submitting my manuscript, at its different stages, to competent critiques. But risks are not eliminated for all that. (ibid., p. 28, my translation) 


\section{Opening}

At least two key questions emerge from the use of the model presented in this paper. First, if the capacity to develop a method of inquiry is necessary contingent and a matter of experiential learning, how does one develop such a strategic mindset? What kind of experience is required in order to nurture an "epic way of knowing" (Munari, $1993 / 2000$, p. 60) characterized by the fact that the researcher "... is not threatened by the discovery of complexity: on the contrary, he [sic] is stimulated and enthusiastic about it." One path to follow may be to learn to embrace disorders (Alhadeff-Jones, 2012b) rather than systematically looking for order. Beyond the individual capacity required in order to do so, it raises another question: how does one privilege and promote such a way of knowing, considering that mainstream research and the majority of academic institutions are based on forms of knowledge organization (e.g., fragmented and compartmentalized) that prevent systematically the unfolding of complex ways of knowing? There is no easy answer; individual capacity and organizational, institutional and cultural dynamics are intertwined. The first step toward the development of a complex method may be to acknowledge the fact that the advance of a critical and complex research process cannot be promoted without questioning and challenging the dominant paradigms that frame scientific inquiry. Another step may involve the recognition of the fact that it is not only a matter of epistemology and methodology, but it is fundamentally a political issue, framed by conflicting interests and diverging worldviews. The following step may be to embrace the fact that beyond power dynamics, it fundamentally carries an ethical dimension.

\section{References}

Alhadeff-Jones, M. (2007). Education, critique et complexité: Modèle et experience de conception d'une approche multiréférentielle de la critique en Sciences de l'éducation. Université de Paris 8 et Université de Lille, France: Atelier National de Reproduction des Thèses.

Alhadeff-Jones, M. (2008). Three generations of complexity theories: Nuances and ambiguities. Educational Philosophy and Theory, 40(1), 66-82.

Alhadeff-Jones, M. (2010). Challenging the limits of critique in education through Morin's paradigm of complexity. Studies in Philosophy and Education, 29(5), 477-490.

Alhadeff-Jones, M., Lesourd, F., Roquet, P., \& Le Grand, J.-L. (2011). Questionning the temporalities of transformative learning in a time of crisis. In Alhadeff-Jones, M., \& Kokkos, A. (Eds.), Transformative learning in time of crisis: Individual and collective challenges. Proceedings of the $9^{\text {th }}$ International Transformative Learning Conference (pp. 394-407). New York \& Athens, Greece: Teachers College, Columbia University \& The Hellenic Open University.

Alhadeff-Jones, M. (2012a). Transformative learning and the challenges of complexity. In E.W. Taylor, P. Cranton \& Associates, Handbook of Transformative Learning: Theory, Research and Practice (pp.178194). San Francisco: Jossey-Bass.

Alhadeff-Jones, M. (2012b). Learning disorders : From a tragic to an epic perspective on complexity. Complicity: An International Journal of Complexity and Education , 9(2), i-vi.

Alhadeff-Jones, M. (2013). Pour une éducation et une formation critiques du rapport au temps. In P. Roquet, M.J. Gonçalves, L. Roger, \& A.P. Viana-Caetano (Eds.) Temps, temporalité et complexité dans les activités éducatives et formatives (pp. 87-103). Paris: L'Harmattan.

Alvesson, M., \& Sköldberg, K. (2000). Reflexive methodology. London: Sage.

Ardoino, J. (1993). L'Approche multiréférentielle (plurielle) des situations éducatives et formatives. Pratiques de Formation / Analyses, 25-26, pp. 15-34.

Barbier, R., \& Pineau, G. (Eds.) (2001). Les eaux écoformatrices. Paris: L'Harmattan.

Boltanski, L., \& Thévenot, L. (1991). On justification: Economies of worth. Princeton: Princeton University Press.

Booth, W. C., Colomb, G. G., \& Williams, J. M. (2003). The Craft of Research. Chicago: The University of Chicago Press.

Denzin, N. K., \& Lincoln, Y.S. (2000). Handbook of qualitative research, second edition. Thousand Oaks, CA: Sage.

Devereux, G. (1967). From anxiety to method in the behavioral sciences. The Hague: Mouton. 
Dominicé, P. (2000). Learning from our lives. Using educational biographies with adults. San Francisco: Jossey-Bass.

Ellsworth, E. (1992). Why doesn't this feel empowering? Working through the repressive myths of critical pedagogy. In C. Luke, \& J. Gore (Eds.), Feminisms and critical pedagogy (pp. 90-119). New York: Routledge.

Fenwick, T., \& Richard, E. (2010). Actor-Network Theory in education. London: Routledge.

Fenwick, T., Richard, E., \& Sawchuk, P. (2011). Emerging approaches to educational research: Tracing the socio-material. London: Routledge.

Gore, J. M. (1993). The struggle for pedagogies, critical and feminist discourses as regimes of truth. New York: Routledge.

Habermas, J. (1971). Knowledge and human interests. Boston: Beacon Press.

Holton, G. (1978). The scientific imagination. Cambridge: Harvard University Press.

Johnson-Bailey, J. (2004). Enjoining positionality and power in narrative work: Balancing contentious and modulating forces. In K. DeMarais, \& S.D. Lapan (Eds.), Foundations for research, methods of inquiry in education and the social sciences (pp. 123-138). Mahwah, NJ: Lawrence Erlbaum.

Le Moigne, J.-L. (1977 / 1984). La théorie du système général. Théorie de la modélisation. Paris: Presses Universitaires de France.

Le Moigne, J.-L. (2001). Le constructivisme. Les enracinements (tome I). Paris: L'Harmattan.

Lefebvre, H. (1961/1991). Critique of Everyday Life (vol. 2). New York: Verso.

Lourau, R. (1997). Implication, transduction. Paris: Anthropos.

Maxwell, J.A. (2005). Qualitative Research Design: An Interactive Approach. Thousand Oaks, CA: Sage Publications.

Morin, E. (1973). Le paradigme perdu: La nature humaine. Paris: Seuil.

Morin, E. (1977/1992). Method. Towards a study of humankind (volume 1: The nature of nature). New York: Peter Lang.

Morin, E. (1977-2004/2008). La méthode [new edition including the six volumes published between 1977 and 2004]. Paris: Seuil

Morin, E. (1980). La méthode (vol. 2) la vie de la vie. Paris: Seuil.

Morin, E. (1982/1990). Science avec conscience. Paris: Fayard.

Morin, E. (1990/2008). On complexity. Cresskill, NJ: Hampton Press.

Morin, E. (1986). La méthode (vol. 3) la connaissance de la connaissance. Paris: Seuil.

Morin, E. (1991). La méthode (vol. 4) les idées. Leur habitat, leur vie, leurs moeurs, leur organisation. Paris: Seuil.

Morin, E., \& Le Moigne, J.-L. (1999). L'intelligence de la complexité. Paris: L'Harmattan.

Munari, A. (1993/2000). Le savoir retrouvé. Genève, Suisse: Université de Genève.

Pineau, G. (Ed.) (1992). De l'air ! Essai sur l'éco-formation. Paris: Païdéia.

Taylor, E. W., Tisdell, E.J., \& Hanley, M.S. (2000). The role of positionality in teaching for critical consciousness: Implications for adult education. Paper presented at the Adult Education Research Conference, University of British Colombia, Vancouver, B.C, Canada.

Torraco, R. J. (2005). Writing Integrative Literature Reviews: Guidelines and Examples. Human Resource Development Review, 4(3), 356-367.

Winnicott, D.W. (1971). Playing and Reality. New York: Basic Books.

Ylijoki, O.-H., \& Mäntylä, H. (2003). Conflicting time perspectives in academic work. Time E Society, 12(1), 55-78. 


\section{About the Author}

Michel Alhadeff-Jones is a Lecturer at the University of Fribourg (Switzerland), and an Adjunct Assistant Professor at Teachers College, Columbia University (USA). He also works as an independent researcher associated with the Laboratoire EXPERICE at the University of Paris 8 (France). He recently founded the Sunkhronos Institute (www.sunkhronos.org) - based in Geneva (Switzerland) - whose mission is to promote critical, complex and transdisciplinary ways of knowing, through educational initiatives and scientific events. Beside his function as Editor-in-Chief of Complicity, he is a Consulting editor for the international journals Adult Education Quarterly and Journal of Transformative Education, an Editorial board member of the international French-speaking journal of adult education Pratiques de Formation / Analyses, the international journal of biographical research Le Sujet dans la Cité, the Polish journal in educational sciences Teraźniejszosć - Człowiek - Edukacja and the Canadian interdisciplinary journal Ibuntu.

Email: complicity.journal@gmail.com Website: www.alhadeffjones.com

(c) Copyright 2013. The author, MICHEL ALHADEFF-JONES, assigns to the University of Alberta and other educational and nonprofit institutions a non-exclusive license to use this document for personal use and in courses of instruction provided that the article is used in full and this copyright statement is reproduced. The author also grants a non-exclusive license to the University of Alberta to publish this document in full on the World Wide Web, and for the document to be published on mirrors on the World Wide Web. Any other usage is prohibited without the express permission of the author. 